\title{
A NEW METHOD TO DESCRIBE THE COMBINED EFFECT OF DRAUGHT AND RADIANT THERMAL ASYMMETRY ON HUMAN WORK PERFORMANCE
}

\author{
Balázs ANDRÁS-TÖVISSI ${ }^{1 *}$, László KAJTÁR ${ }^{1}$
}

\begin{abstract}
Human resources are the most important elements of economic units; thus, the efficiency of human work is of crucial importance. Work efficiency can be achieved only in an environment offering optimal thermal comfort. The present study makes use of human subject experiments in order to investigate the joint effect of draughts and warm ceilings on work performance. During the experiments, 10 thermal environments with $5 \mathrm{ra}$ diant thermal asymmetries and 2 draught rates were investigated. The most important outcome of the research is the presentation of the combined effect of a draught and a warm ceiling on work performance.
\end{abstract}

\section{Address}

1 Dept. of Building Services and Process Engineering, Budapest University of Technology and Economics, Budapest, Hungary

* Corresponding author: andras_balazs@yahoo.com

\section{Key words}

- Thermal comfort

- Productivity,

- Radiant thermal asymmetry,

- Draught,

- Joint effect,

- Human subject measurement.

\section{INTRODUCTION}

The efficiency of human work is of crucial importance, as human resources are the most important elements of economic units (Wargocki, Wyon, 2013). Therefore, creating a comfort environment that maximizes work efficiency (Wargocki, Wyon, 2003) is a primary consideration when planning buildings.

The most well-known thermal comfort indicators are Predicted Mean Vote (PMV) and Predicted Percentage of Dissatisfied (PPD). These two indicators are complemented by local discomfort factors. The separate effect of local discomfort factors is known (Bánhidi, Kajtár, 2000), but the literature on their combined effect is currently incomplete.

This article aims to address the lack of literature on the combined effect of draughts and warm ceilings on work performance.

Throughout the research, the work speed and accuracy were investigated at 5 levels of radiant temperature asymmetry and 2 draught rates in order to answer to the following questions:

- how does the working speed of people change at draughts rate of $15 \%$ and $25 \%$ ?

- how does the accuracy of the work of people change at draught rates of $15 \%$ and $25 \%$ ?

\section{METHODS}

The novelty of the method exanimated consists in the fact that it investigates the joint effects of local discomfort factors and offers new insights on their impact on human thermal comfort and work performance.

We investigated the joint effect of local discomfort factors at the Macskásy Comfort and Air Conditioning Laboratory of the Budapest University of Technology and Economics. The configuration of the laboratory is illustrated in Fig. 1.

Along with the assessment of the local discomfort factors, we investigated the joint effect that the parameter pairs of a hot ceiling and a draught have on thermal comfort. Meanwhile, we kept the thermal environment neutral at all times, in accordance with the PMV model. At the height of the heads of the human subjects, the PMV value respected an interval $(-0.2-+0.2)$. For all of the examined cases, the PPD remained below $6 \%$.

We had to take the following measures into account in order to create the optimal thermal environment according to the PMV model and, in the meantime, also maintain the draught and the radiant thermal asymmetry at the rate desired:

- Determining the surface of the boundary structures. This step allowed the desired temperature asymmetry to be set; 


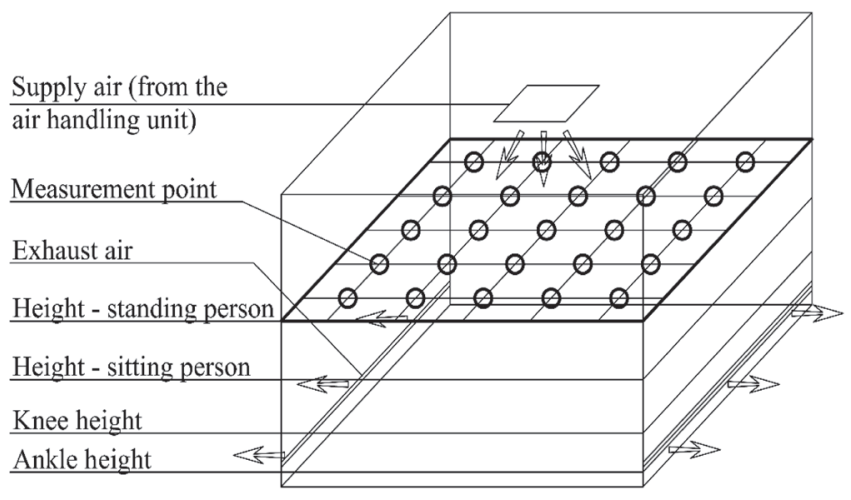

Fig. 1 Scheme of the comfort chamber

- Determining the air temperature supply. The temperature and volume of the air supply ensure a thermally stationary state of the measuring chamber. However, both parameters also influence the expected sensation of a draught;

- Fine-tuning the airflow in the measurement chamber. This was done for the purpose of achieving and maintaining the desired draught value.

When determining the wall temperatures, the following settings and values were assumed: the heat transfer coefficient of the exterior wall: $0.24 \mathrm{~W} / \mathrm{m} 2 \mathrm{~K}$; the heat transfer coefficient of the window: $1.15 \mathrm{~W} / \mathrm{m} 2 \mathrm{~K}$; outside temperature: $-15^{\circ} \mathrm{C}$; temperature of the room below the modelled chamber: $10^{\circ} \mathrm{C}$. Considering the aforementioned parameters, the temperature of the walls and floors was set at $20.5^{\circ} \mathrm{C}$. Knowing these values made it possible to define the surface temperature of the warm ceiling in relation to the temperature of the floor. The ceiling temperature had values of $5,7,10,12$, and respectively, $15^{\circ} \mathrm{C}$, above the floor temperature.

The presence of a warm ceiling implies that heat has been added into the chamber. The experiment was aimed at generating thermally stationary states, i.e., the heat of the warm ceiling needed to be counterbalanced in some way. The most suitable way of doing so was by an inflow of a colder supply of air.

Throughout the human subject measurements, the sustainability of the stationary state was continuously monitored and verified through measurements.

Two draught rates and five radiant thermal asymmetry values were investigated during the research. Their combinations resulted in a total of 10 different cases. A control and tuning test were completed for each of them. The measurement point used in the tests was in the center of the space, at a height of 1.1 meters. At this measurement point, we made sure that the PPD stayed under $6 \%$ throughout the whole extent of the measurements. Meanwhile, the draught rates and radiant thermal asymmetries between the floor and the ceiling were also respected.

Throughout the measurements, the relevant parameters of the air jet (the character, orientation and symmetry) could be controlled through a ceiling diffuser, which had adjustable blades. Visualization experiments and instrumental measurements were conducted on the air jet.

\subsection{Instrumental measurements}

\subsection{1 description of the instrumental measurements}

The spatial distribution of the factors influencing thermal comfort was assessed in the comfort chamber displayed in Fig. 1. This chamber had a height of $3 \mathrm{~m}$ and a floor surface area of $4 \mathrm{x} 4 \mathrm{~m}$. The measurements were aimed at investigating the following parameters: temperature and humidity, spatial distribution of the air velocity, turbulence intensity, mean radiant temperature, PMV, PPD, and the draught rate.

Fig. 1 shows the four fields in which the measurements were made: at $0.15 \mathrm{~m}$ (ankle height), at $0.45 \mathrm{~m}$ (knee height), at $1.1 \mathrm{~m}$ (head height of a sitting person) and at $1.7 \mathrm{~m}$ (head height of a standing person).

Furthermore, the figure also shows the spatial locations where the measurement points were recorded. The point at the center of the measuring plane is of particular interest. It is made up of an average of 5 points, i.e., one of them placed in the center of the plane and 4 points placed at the angles of a $60 \mathrm{~cm}$ side square.

The parameters that affect thermal comfort were partially calculated and partially measured. Tab. 1 shows the parameters in question, as well as the measurement errors for each one.

Tab. 1 Calculated and measured parameters

\begin{tabular}{|l|c|c|}
\hline Parameter & $\begin{array}{c}\text { Measured/ } \\
\text { Calculated }\end{array}$ & $\begin{array}{c}\text { Error of } \\
\text { measurement }\end{array}$ \\
\hline Air and mean rad. temperature & Measured & $0.1^{\circ} \mathrm{C}$ \\
Air velocity & Measured & $0.03 \mathrm{~m} / \mathrm{s}+0.04$ \\
Air humidity & Measured & $1.8 \%+0.007$ \\
Thermal insulation of clothing & Calculated & Measured value \\
Metabolic rate & Calculated & - \\
Intensity of turbulence & Calculated & - \\
PMV & Calculated & - \\
PPD & Calculated & - \\
\hline
\end{tabular}

\subsubsection{Results of the instrumental measurements}

Throughout the instrumental measurements, a vast amount of data was obtained. Out of all of this data, we focus in this article on the presentation of the spatial distribution of the DR and PMV values at a radiant thermal asymmetry of $15{ }^{\circ} \mathrm{C}$ and DR of $15 \%$. These are shown in Diagrams 1 and 2. The vertical (y) axis of the graphs shows the value of the examined variable, while the axes defining the base planes ( $\mathrm{x}$ and $\mathrm{z}$ ) show the spatial dimensions.

We calculated the PMV from several measured parameters. The experiment was planned in a way that the PMV would be maintained at an optimal interval $(-0.2-+0.2)$ in the center of the space, at a height of 1.1 meters. Throughout the experiment it was noted that the expected value of the dissatisfied (PPD) was the smallest on the measurement plane, i.e. in the center of the space. Another important finding was that, although the PMV value was distributed inhomogeneously, the expected value of the dissatisfaction stayed within the interval $(-0.2-+0.2)$.

We noticed greater differences caused by the inhomogeneity of the space in the case of the DR. This is due to the significant difference between the mean draught rate of the area marked as the center of the space (approximately 15\%) and the value measured next to the wall (below $5 \%$ ). For each parameter pair of draught and asymmetry, the value of the PPD stayed below $6 \%$. Further, the difference in the radiant thermal asymmetry temperature between the ceiling and the floor was kept at the planned value. The same was also true for the DR.

The best way to evaluate the dissatisfaction caused by a warm ceiling at a draught effect of $15 \%$ and $25 \%$ was to perform human subject tests. 
Predicted Mean Vote,

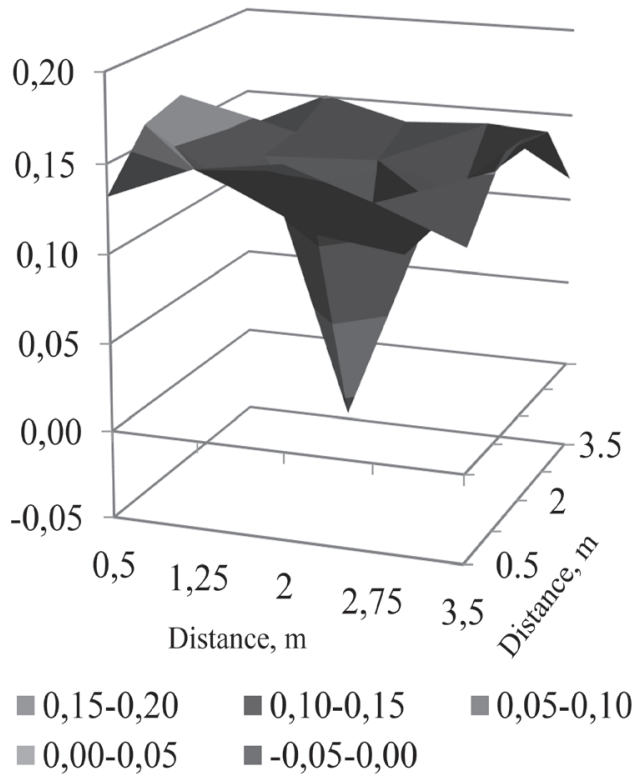

Diagram 1 Distribution of PMV in spac

\subsection{Human subject measurements}

Fig. 1 illustrates the comfort chamber where the human subject measurements were conducted. A number of experiments related to thermal comfort were performed during the measurement series. The human subjects provided votes related to their rate of dissatisfaction with the warm ceiling. Their votes had values on a continuous scale between 0 and 1 , where 0 meant a dissatisfaction of $0 \%$, while 1 meant a dissatisfaction rate of $100 \%$.

When designing, implementing and evaluating the measurements, we took into consideration the methodology used in human subject measurements as found in the current literature (Wargocki, Wyon, 2013; Toftum, 2002; Wang et al, 2018; Wu et al, 2017; Lan, Lian, 2010; Choi, Yeom, 2017; He et al, 2016)

Tab. 2 shows the methodology used in the human subject measurements:

Acoustic disturbances were ruled out during the measurements. The quality of the indoor air did not cause any discomfort either, due to the high rate of the air exchange. Furthermore, much attention was paid to providing proper visual comfort.

Each measurement session was made up of six repetitive measurement blocks, each of them lasting for thirty minutes. In this way, we collected paper-based information from the individuals examined. The information was then processed and evaluated using mathematical methods.
Draught rate, $\%$

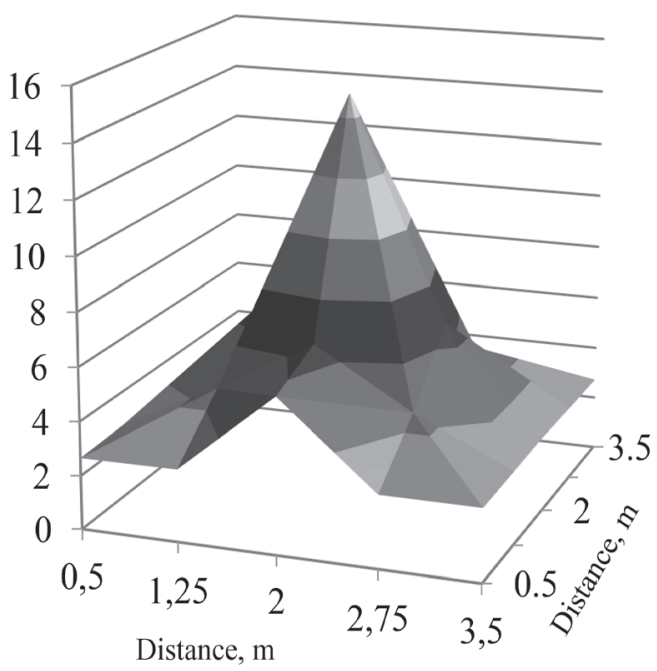

$$
\begin{array}{llll}
\square 14-16 & \square 12-14 & \square 10-12 & \square-10 \\
\square 6-8 & \square-6 & \square-4 & \square-2
\end{array}
$$

Diagram 2 Distribution of DR in space

\section{THE MATHEMATICAL METHODOLOGY OF THE EVALUATION}

During the analysis of the results, we examined the connections between the thermal comfort and human work performance in different situations. Two sets of data using two different mathematical methods were contrasted at all times throughout the study. We assessed the results by using the Welch test and the Mann-Whitney exact test. Due to the differences in the nature of these two methods, we could safely accept the dependency or independence of the two sets of data if we got the same results by applying both methods.

The Welch test (or d-test) is a parametric test from a category of statistical hypothesis tests. Its significance level was set at 0.05 .

The Mann-Whitney test is a non-parametric test which operates with rankings of values. As the null hypothesis, it states that there is an equal probability of $50 \%$ that a randomly selected element from one population is greater than any randomly selected element from a second population. Its confidence interval was defined as 0.95.

\section{RESULTS}

When measuring the efficiency of human work, both the accuracy and the speed of the work must be taken into account. A decrease in accuracy in favour of speed, or vice versa, is known as the speed-accuracy trade-off phenomenon.

Tab. 2 Methodology of the human subject measurements

\begin{tabular}{|l|l|}
\hline Number of subjects & 20 subjects: 10 men, 10 women \\
\hline Number of examined cases & 10 cases: 5 thermal asymmetries, 2 DR values \\
\hline Duration of measurement & 3 hours (one comfort environment for each measurement) \\
\hline Order of the comfort environments & Random \\
\hline
\end{tabular}


Speed, Women, $\mathrm{DR}=15 \%$

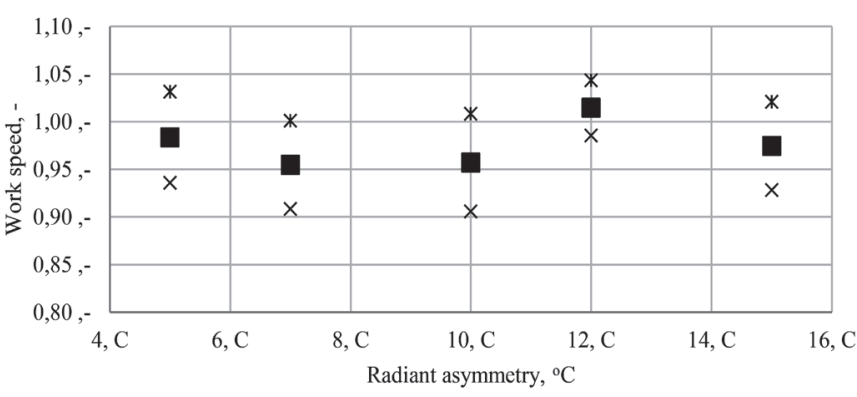

- Speed $\times$ Low $*$ High

Diagram 3 Work speed as a function of radiant asymmetry Women, $D R=15 \%$

Speed, Men, DR=15\%

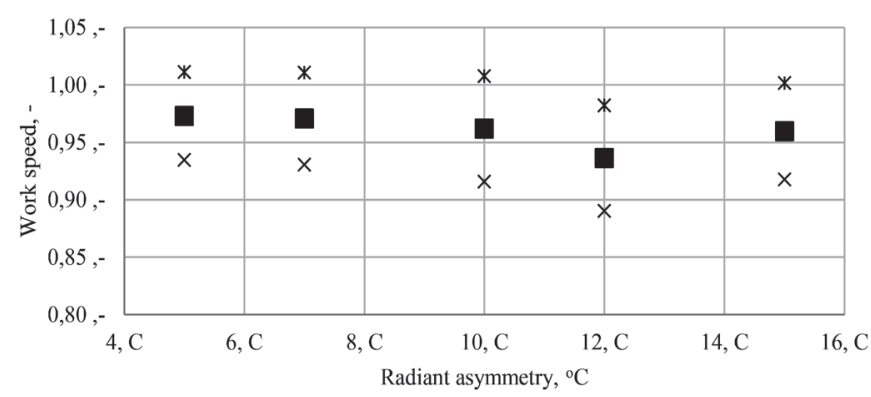

- Speed $\times$ Low $*$ High

Diagram 5 Work speed as a function of radiant asymmetry - Men, $D R=15 \%$

Speed, Women and Men, DR=15\%

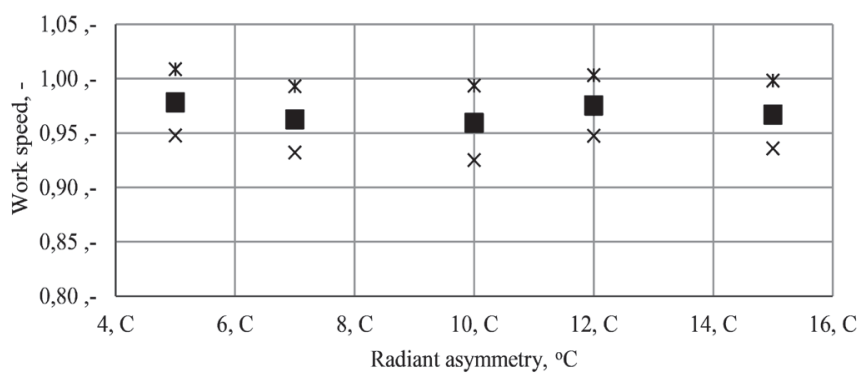

- Speed $\times$ Low $*$ High

Diagram 7 Work speed as a function of radiant asymmetry - Women and Men, $D R=15 \%$

Speed, Women, $\mathrm{DR}=25 \%$

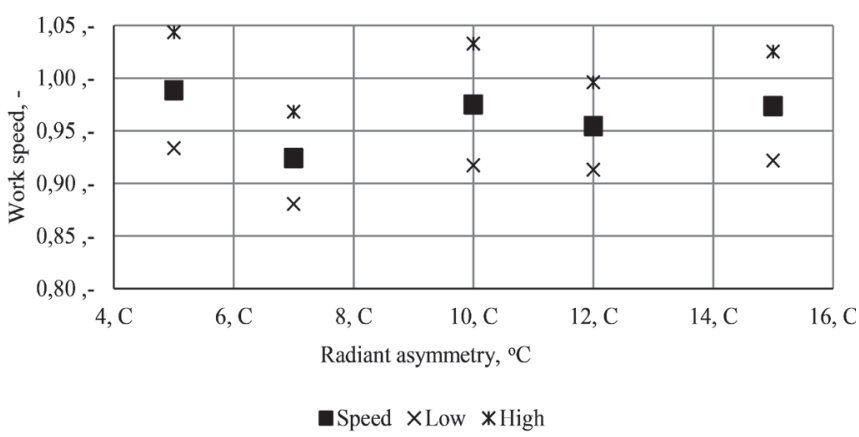

Diagram 9 Work speed as a function of radiant asymmetry Women, $D R=25 \%$
Accuracy, Women, $\mathrm{DR}=15 \%$

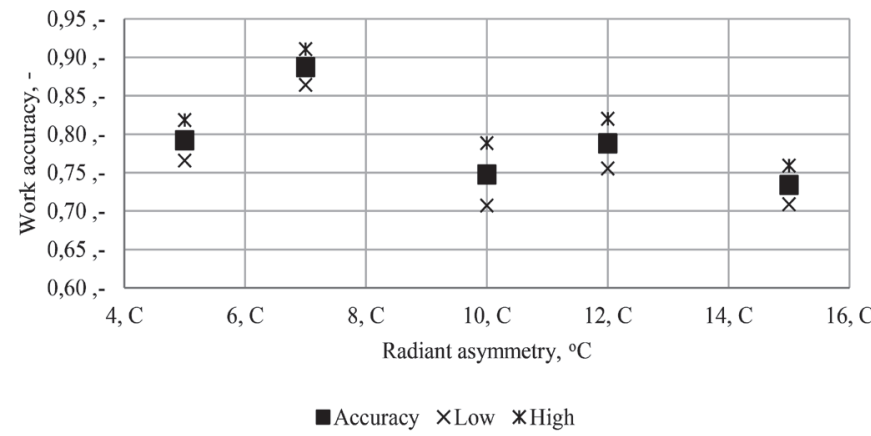

Diagram 4 Work accuracy as a function of radiant asymmetry Women, $D R=15 \%$

Accuracy, Men, DR=15\%

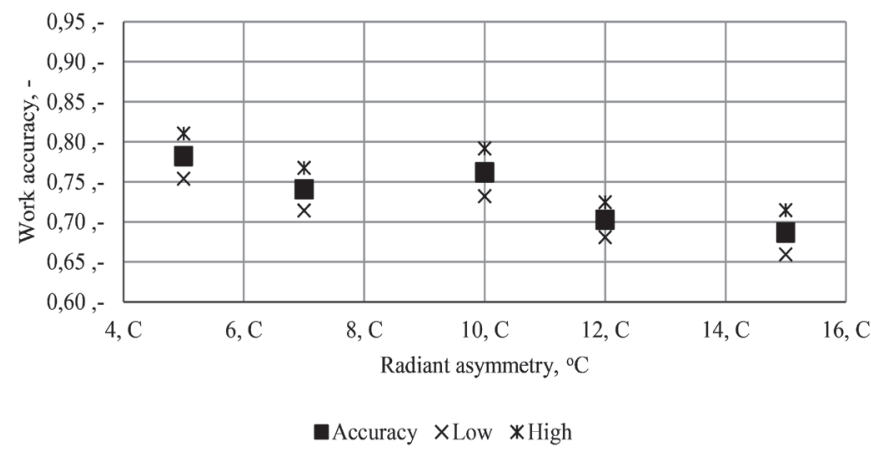

Diagram 6 Work accuracy as a function of radiant asymmetryMen, $D R=15 \%$

Accuracy, Women and Men, DR=15\%

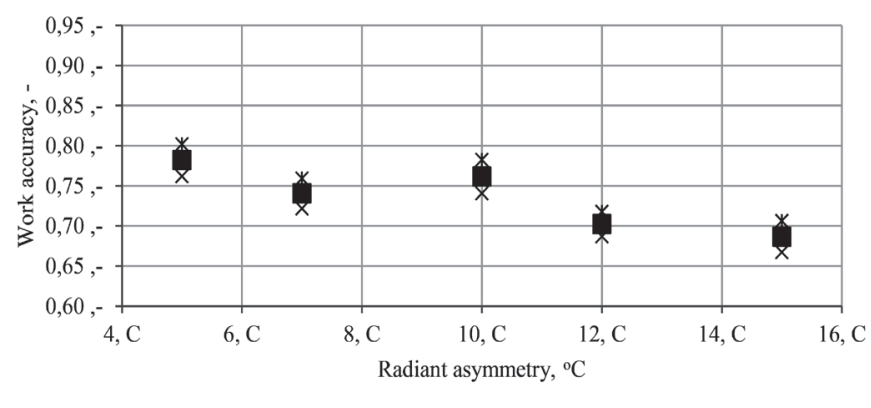

-Accuracy $\times$ Low $*$ High

Diagram 8 Work accuracy as a function of radiant asymmetryWomen and Men, $D R=15 \%$

Accuracy, Women, $\mathrm{DR}=25 \%$

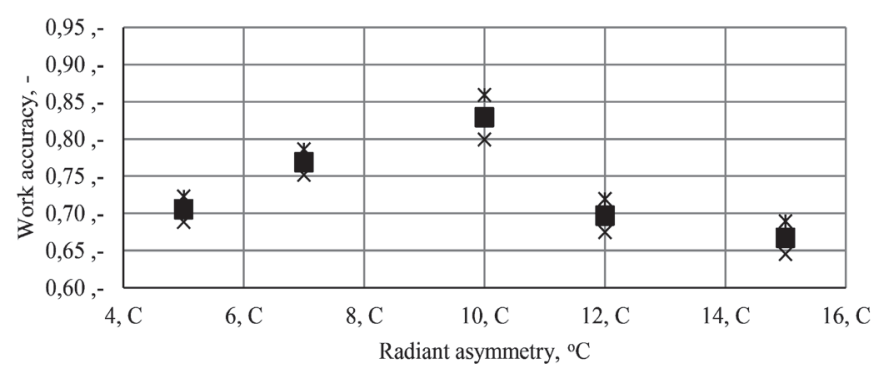

Accuracy $\times$ Low $*$ High

Diagram 10 Work accuracy as a function of radiant asymmetryWomen, $D R=25 \%$ 
Speed, Men, $\mathrm{DR}=25 \%$

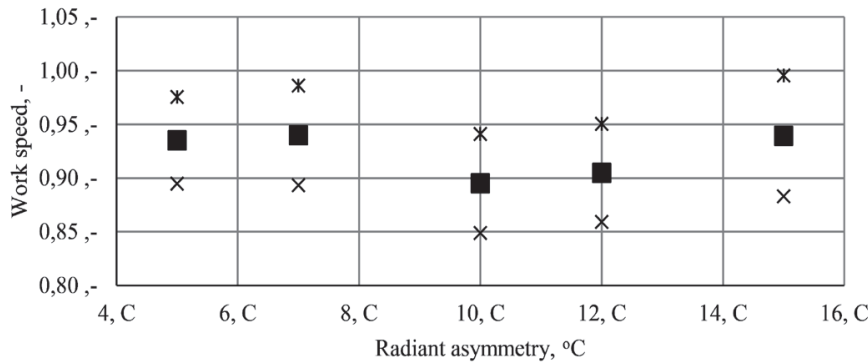

- Speed $\times$ Low $*$ High

Diagram 11 Work speed as a function of radiant asymmetry - Men, $D R=25 \%$

Speed, Women and Men, DR=25\%

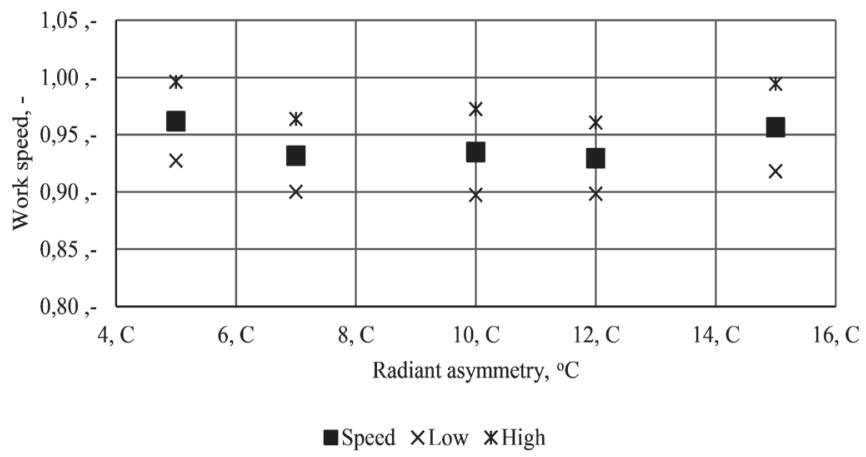

Diagram 13 Work speed as a function of radiant asymmetryWomen and Men, $D R=25 \%$

Both of the above factors were determined in comparison with an individually defined level. When determining the level in question, the following criteria were taken into account:

- exclusion of the learning effect;

- exclusion of thermal comfort disturbances.

In order to exclude the learning effect, the subjects performed the work performance tests used in the particular human subject experiments prior to performing the comparative tests. The results of these tests were not taken into account but were only used to familiarize the individuals with the tasks. On the day after completing the familiarization tests, the subjects performed 4 work performance tests in an

Speed and Accuracy, Women and Men, $\mathrm{DR}=15 \%$

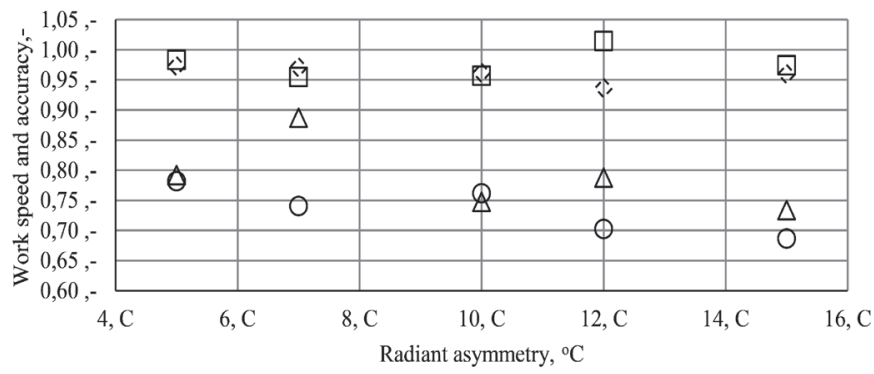

$\square$ Speed, Women, $\mathrm{DR}=15 \% \quad \Delta$ Accuracy, Women, $\mathrm{DR}=15 \%$ $\because$ Speed, Men, $\mathrm{DR}=15 \% \quad$ OAccuracy, Women, $\mathrm{DR}=15 \%$

Diagram 15 Work speed and accuracy depending on radiant asymmetry - Women and Men, $D R=15 \%$
Accuracy, Men, $\mathrm{DR}=25 \%$

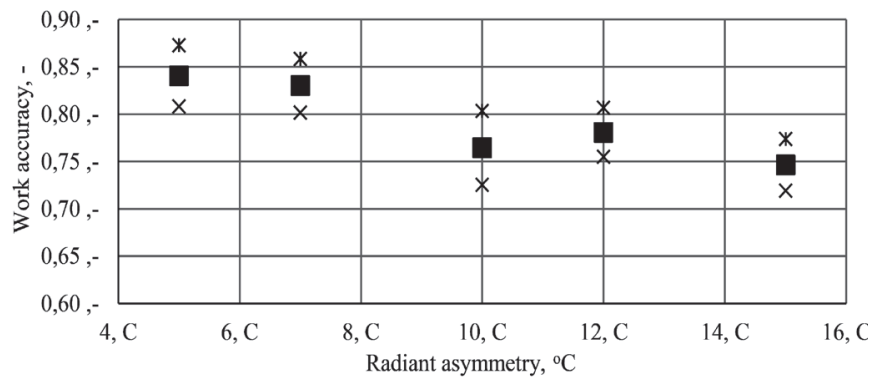

-Accuracy $\times$ Low $*$ High

Diagram 12 Work accuracy as a function of radiant asymmetryMen, $D R=25 \%$

Accuracy, Women and Men, $\mathrm{DR}=25 \%$

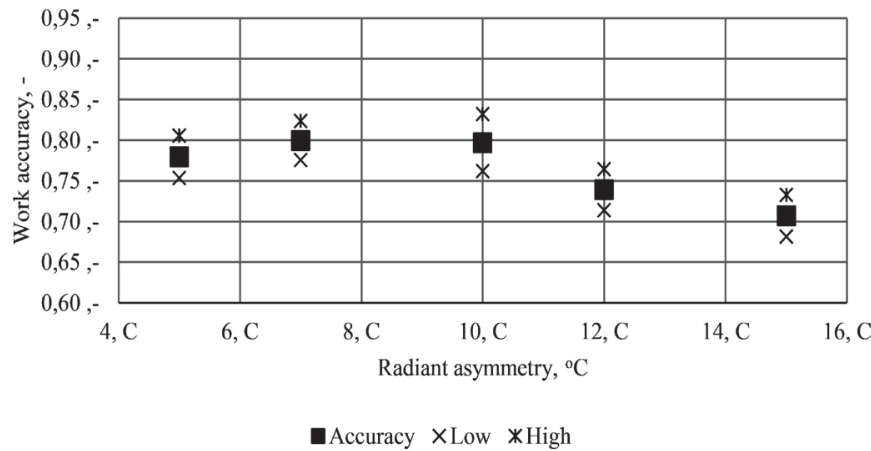

Diagram 14 Work accuracy as a function of radiant asymmetryWomen and Men, $D R=25 \%$

environment they considered ideal. The average of the last three tests was considered the reference level for each subject when defining the speed and accuracy of their own work.

Diagrams $1-6$ show the work speed and accuracy with respect to the radiant asymmetry, taking into account (1) only the female subjects, (2) only the male subjects, as well as (3) all the human subjects.

\section{DISCUSSION}

The results presented in Chapter 4 were identified and examined using the mathematical statistical methods presented in Chapter 3,

Speed and Accuacy, Women and Men DR $=25 \%$

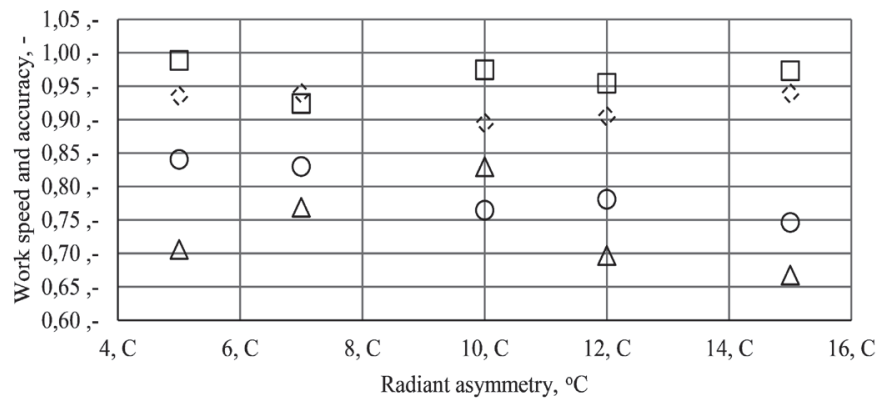

口Speed, Women, $\mathrm{DR}=25 \% \quad \Delta$ Accuracy, Women, $\mathrm{DR}=25 \%$

$\leadsto$ Speed, Men, $\mathrm{DR}=25 \% \quad$ OAccuracy, Men, $\mathrm{DR}=25 \%$

Diagram 16 Speed and accuracy of work depending on radiant asymmetry - Women and Men, $D R=25 \%$ 
i.e., the difference in work performance, based on gender, in the comfort environment created by the draught and the warm ceiling.

\subsection{Work performance depending on gender}

\subsubsection{Work performance depending on gender, at $d r=15 \%$}

Diagram 15 shows the changes in accuracy and speed for DR = $15 \%$, depending on the gender.

When comparing the data points, we used two mathematical approaches, as described in Section 3, i.e., the Welch test and the Mann-Whitney exact test. A conclusion was only accepted if both of the aforementioned methods led to the same result. In this section we investigated the gender differences and the dependencies and tendencies between the values found at different asymmetries.

At a DR of $15 \%$, there was no significant change in work speed, considering an asymmetry of $5,7,10,12$ and $15^{\circ} \mathrm{C}$. Thus, for the DR $=15 \%$, in the interval of $5-15^{\circ} \mathrm{C}$, the radiant asymmetry caused by the warm ceiling had no significant effect on the speed of the work of either the women or men.

Similarly, when examining the accuracy of the work with respect to radiant asymmetry, it can be stated that the mean value of the change in accuracy for the men was steadily decreasing with a good approximation. In the case of the women, it can be stated that their maximum working accuracy could be found at a temperature of $7^{\circ} \mathrm{C}$. In order to support this statement, it must be proven that the figures defining the precision of the work are fully independent for each pair of asymmetries. With the aim of consolidating the proof, we also tested the proposition with the Welsh test and the Mann-Whitney exact test. In both cases, it could be proved that for the comparison pairs of $5-7,7-10,7-12$, and $7-15^{\circ} \mathrm{C}$, the accuracy values examined are significantly different, since each pair of data differed by at least a 95\% significance level according to the Welch theorem; and, in the case of the Mann-Whitney exact test, the asymptotic bilateral significance did not exceed the value of 0.05 for any value pair comparison.

According to the average values, it can be stated that with a draught rate of $\mathrm{DR}=15 \%$ and a temperature asymmetry of $5,7,10$, 12 and $15^{\circ} \mathrm{C}$, the accuracy of the work of the women is maximal with an asymmetry of $7{ }^{\circ} \mathrm{C}$; in the case of the men, the accuracy of the work showed less change and decreased with a good approximation as the radiant asymmetry increased.

\subsubsection{Work performance depending on gender, for $d r=$ $25 \%$}

Diagram 16 shows the change in the accuracy and speed of work for $\mathrm{DR}=25 \%$, depending on the gender.

In this case, the testing method was also based on the Welsh test and the Mann-Whitney exact tests. Here, the values presented in Section 5.1.1 were tested at a higher draught rate.

With a draught rate of $\mathrm{DR}=25 \%$ and a temperature asymmetry of $5,7,10,12$ and $15^{\circ} \mathrm{C}$, there was no significant difference in the speed of the work. It can be stated that for $\mathrm{DR}=25 \%$, the radiant asymmetry of $5-15^{\circ} \mathrm{C}$ caused by the warm ceiling had no significant effect on the working speed of either the women or men.

For similar parameter groups, the change in accuracy of the work was also examined. It can be stated that the accuracy of the men constantly decreased with a good approximation and that there was little difference between the mean values. In the case of the women, it can be stated that, at a DR value of $25 \%$ and an asymmetry of $5,7,10,12$ and $15{ }^{\circ} \mathrm{C}$, the maximum accuracy level was reached at an asymme- try of $10{ }^{\circ} \mathrm{C}$. Up to this value, the mean values of the working accuracy increased; after this level, they decreased. The method described in Section 3 was used to prove the maximum value. Also, in using the Welsh and Mann-Whitney methods, it can be proven that when comparing the $5-10,7-10,10-12$ and $10-15{ }^{\circ} \mathrm{C}$ data pairs, the set investigated is significantly different.

According to the mean values of the accuracy of the work and the independence of the measurement data sets, it can be stated that with a draught effect of $\mathrm{DR}=25 \%$ and a temperature asymmetry of 5, 7, 10,12 and $15{ }^{\circ} \mathrm{C}$, the accuracy of the women's work reached its maximum at $10{ }^{\circ} \mathrm{C}$. In the case of the men, the accuracy of the work was more constant and decreased with a good approximation as the radiant asymmetry increased.

\section{CONCLUSIONS}

Considering Sections 5.1.1 and 5.1.2, the following observations can be made when jointly examining the effects of a warm ceiling and draught as a function of radiant thermal asymmetry:

- for $\mathrm{DR}=15 \%$, the warm ceiling-caused asymmetric radiation of 5 to $15{ }^{\circ} \mathrm{C}$ had no significant effect on the work speed of either the women or men.

- for $\mathrm{DR}=15 \%$ and $5,7,10,12$ and $15^{\circ} \mathrm{C}$ temperature asymmetry, the accuracy of the women's work reached its maximum at $7{ }^{\circ} \mathrm{C}$; the accuracy of the men's work was less variable and decreased with a good approximation as the asymmetric radiation increased.

- for DR $=25 \%$, the warm ceiling-caused radiant asymmetry of $5-15^{\circ} \mathrm{C}$ had no significant effect on the working speed of either the women or men.

- for DR $=25 \%$ and $5,7,10,12$ and $15{ }^{\circ} \mathrm{C}$ thermal asymmetry values, the accuracy of the women's work was maximal at 10 ${ }^{\circ} \mathrm{C}$ asymmetry; the accuracy of the men's work was less variable and decreased with a good approximation as the asymmetric radiation increased.

\section{Acknowledgements}

We wish to thank the Hungarian National Research, Development and Innovation Office (OTKA No. 124777) and the FIKP Artificial Intelligence - Smart City program for partially supporting this work.

We also thank all the companies which provided material and professional assistance to the Macskásy Climate and Comfort Laboratory. 


\section{REFERENCES}

Bánhidi, L. - Kajtár, L. (2000) Komfortelmélet. BME Technical Press, Budapest.

Choi, J. - Yeom, D. (2017) Investigation of the relationship between thermal sensation of local body area and whole body in an indoor built environment. Energy and Buildings, No. 149, pp. 204-215.

He, Y. - Li N. - Zhang, W. - Peng, J. (2016) Overall and local thermal sensation and comfort in air-conditioned dormitory with hot-humid climate. Building and Environment, No. 101, pp. 102109.

Lan, L. - Lian, Z. (2010) Application of statistical power analysis How to determine the right sample size in human health, comfort and productivity research. Building and Environment, No. 45, pp. 1202-1213.

Toftum, J. (2002) Human response to combined indoor environment exposures. Energy and Buildings, No. 34, pp. 601-606.
Wang, J. - Wang, Z. - de Dear, R. - Luo, M. - Ghahramani, A. - Lin, B. (2018) The uncertainty of subjective thermal comfort measurement. Energy and Buildings, No. 181, pp. 38-49.

Wargocki, P. - Wyon, P. D. (2003) Ten questions concerning thermal and indoor air quality effects on the performance of office work and schoolwork. Building and Environment, No. 51 2012, pp. 234-241.

Wargocki, P. - Wyon, P. D. (2013) Providing better thermal and air quality conditions in school classrooms would be cost-effective. Building and Environment, No. 59 2013, pp. 581-589.

Wu, X. - Liu, Y. - Liu, G. - Wang, F. - Wang, Z. (2017) Effect of Supply Air Temperature on Indoor Thermal Comfort in a Room with Radiant Heating and Mechanical Ventilation. Energy Procedia, No. 121, pp. 206-213. 